\title{
Empirical study of heat transfer at input area of turbojet blades
}

\author{
Mahdi Poormohamadi Raad, Alireza Roudbari \\ MSC of Mechanical Engineering, KNToosi University \\ Associate Professor of ShahidSattari University
}

\begin{abstract}
The barriers against the flow or jags can be used, increasing of heat transfer rate. Turbojet blade cooling, heat convertors and solar air heater are the devices that jags used in them. Arrangement and geometry of jags are effective on heat and pressure transfer.In present study the heat transfer at turbojet turbine blades entrance has been studied empirically. The thin and square jags were compared distinctly.The air was imported to the conduit in 10000 to 30000 Reynolds. Three step towards the jags height equal to 10, 20, 40, and 3jags height towards the hydraulic diameter of conduit equal to 0.068. 0.137 And 0.205 were considered and jags were implemented in $90^{\circ}$ attack angle. In experimented domain, it was revealed that heat would be increased with reduction of step to jags height ratio and increasing of jags height to hydraulic diameter of conduit ratio.
\end{abstract}

Keywords: Jag, heat transfer improvement, turbojet, constant heat flux, jag step, jag height.

\section{Introduction}

During the recent years, jags have the considerable applications such as turbine cooling, solar heaters and heat convertors. Turbojet engines mainly rely on generated power obtained from the output gases. In turbojet engines, the air enters to the compressor at first and compacted. However, this air is not suitable for combustion because of its high speed and the most of fuel wasted without combustion. Due to that, the air sent to diffuser or speed reducer to reduce its speed. In diffuser, at first, the air speed is reduced and then its temperature and pressure increases; after that this air transmitted to the combustion chamber. Figure one shows that there are some different ways for cooling the gas turbine blade such as spray, cooling with fluid film, using the jags and the form of cooling paths (Han et al, 1984).

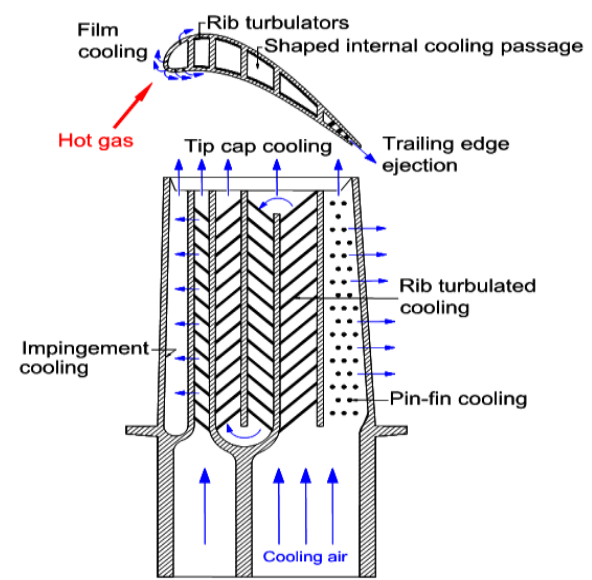

Fig1. Different ways of cooling the gas turbine blades (Han et al, 1984)

In this article, cooling the gas turbine blades at entrance areawill be done, using some kind of turbulence maker called jags. Although, using the jags increase the heat transfer but it caused the pressure reduction. Therefore, it is necessary to study both heat transfer increasing and pressure reduction. The rate of heat transfer into the canal is low for the air, because the air has the low heat conductivity and capacity (Gao et al, 2006). Low heat transfer depends on a sublayer under the transfer surface that should be broken for the heat transfer improving. Flow fluctuation is the one of those ways via the bed roughing (Aharwala et al, 2008). Using the jags can be effective in heat transfer and coefficient increasing.

Han et al. (1978) evaluated the jags form, attack angle and the step ratio to jags height on friction coefficient; in a rectangular canal with two rough walls,Figure 2 describes them. 


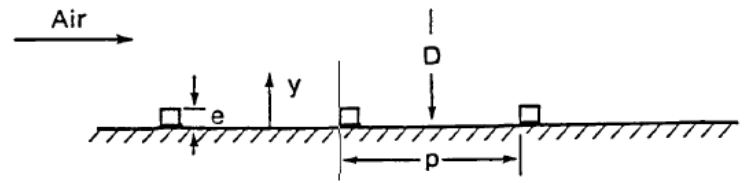

Fig2. Important geometric parameter of jags (Han et al, 1978)

Han et al.(1992) and Kiml et al.(2001) reported that attack angle of jags with $60^{\circ}$ has the better results than $45^{\circ}$.Lau et al. (1991) evaluated the heat transfer and pressure reduction in the completely expanded area in a square canal with discrete transverse jags. They found that heat transfer coefficient in discrete state is 10 to $15 \%$ more than continuous state.Cho et al, 2000, experimented the effect of attack angle and the number of discrete jags. They understood that the gap between the jags accelerate the flow and increase the heat transfer.Doherty et al, 2001, studied the effect of jags in a canal by the numerical and experimental methods. They found that when the canal dimension equals to 0.37 and the ratio of step than jags equals to 10 is the optimum state. Liou et al, 1993, studied the numerical and empirical methods of heat transfer in a canal with asymmetric jag locations. Also Ryu et al, 2007, evaluated the jag's form such as square, triangular and semicircular forms in heat transfer of turbulent flow in a wide range of Reynolds numbers. Billen et al, 2009, assessed the characteristics of heat transfer and friction for the turbulent and expanded airflow in a canal with circular, rectangular and trapezoidal furrows, empirically.

Conclusions show the importance of jags in heat transfer mechanisms and devices such as solar heaters. However, the necessity of more studies in this field is obvious for quantitative and qualitative improvements. For this aim, an educational set for studying the jags effect has been designed in this article.

\section{Empirical device manufacturing}

Evaluating the step and height of jag in heat transfer, an empirical device has been designed and made. Figure 3 shows the general view of device.

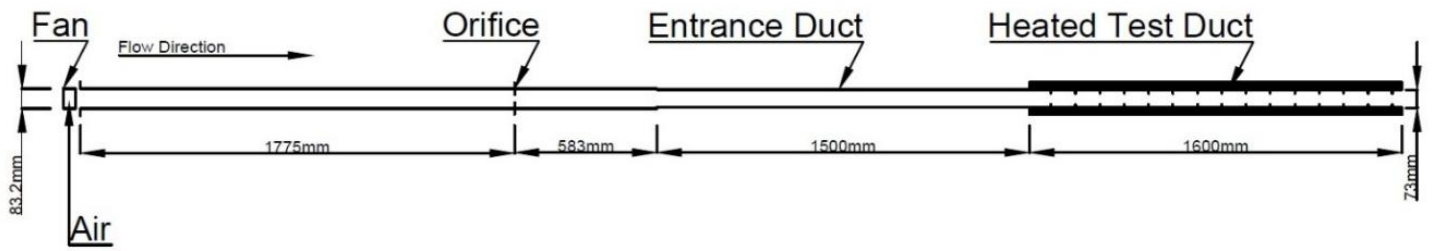

Fig3. Schematic of Empirical Device

A fan located at the beginning of device for the flow conduction into the canal. Its power is adjustable and the flux and Reynolds can be controlled. The orifice located then, the mass flux can be calculated by it. Figure 4 shows the fan.

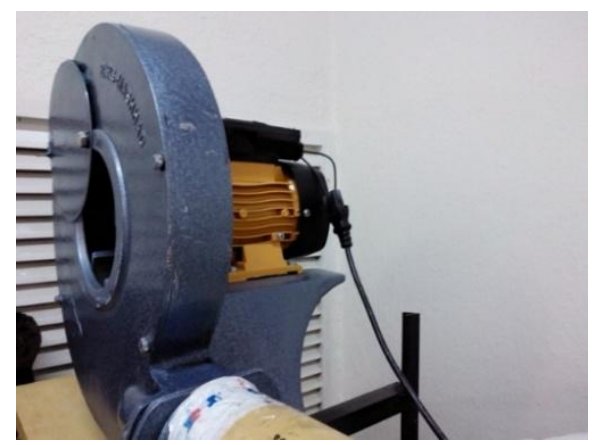

Fig4. A figure of used fan

Figure 5 shows the orifice. A punched surface located against the flow direction; it causes the pressure loss. A liquid manometer used to measure this loss. 


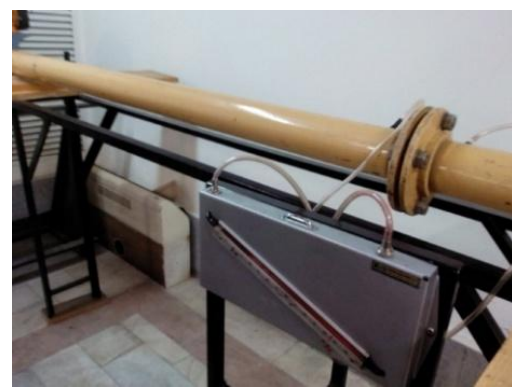

Fig5. The Orifice

Figure 6 shows that after the orifice a glass canal, 76*76 mm cross section with $1524 \mathrm{~mm}$ length, located to generate a completely expanded flow.

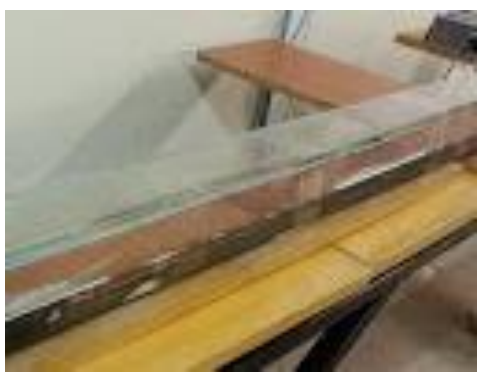

Fig6. A view of glass canal

Heating area located after the glass canal. This area is a steel canal with $76 * 76 \mathrm{~mm}$ cross section, 1600 $\mathrm{mm}$ length and $3 \mathrm{~mm}$ thickness. Electrical heaters with plate form utilized for the heating process with specific resistance and providing the $1000 \mathrm{~W}$ power. An important property of this heater is the continuous heat flux. Thermistors used, measuring the temperature at various points. Figure 7 shows the thermistors locating way into the canal.

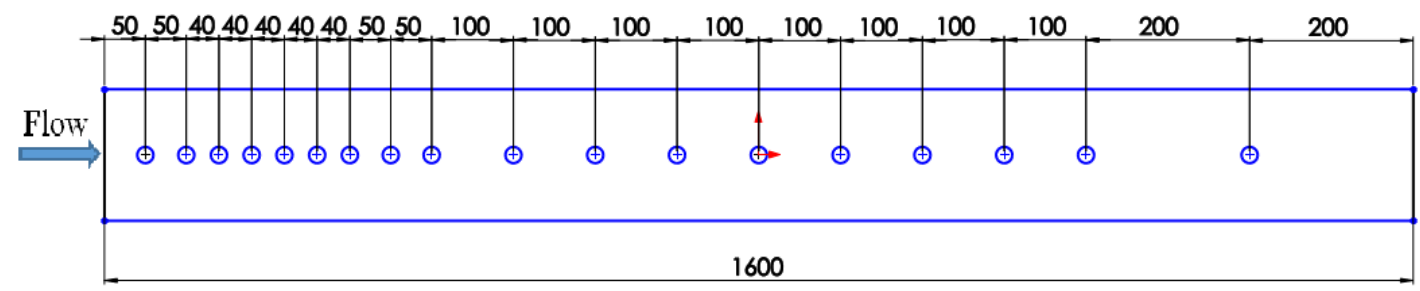

Fig7. Thermistors locating way into the canal

Wooden jags with $5 \mathrm{~mm}$ thickness utilized, fluctuating the flow (figure 8).

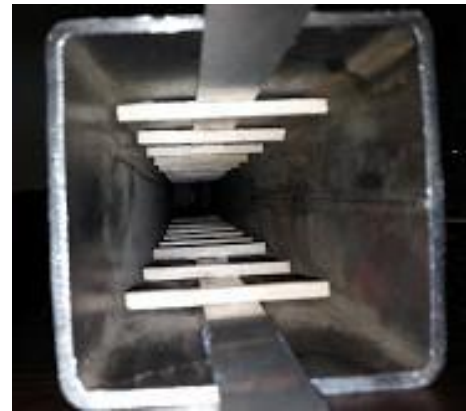

Fig8. A view of used jags in canal

Ratio of P/e equals to 10,20 and 40. e/D ratio equals to $0.068,0.137$ and 0.205 . The jags located in $90^{\circ}$ attack angle in two opposite surfaces. An auto-trans device or mono-phase voltage regulator, TDGC2-3 model, has been used for the generating and controlling the different heat fluxes on rough bed and without jag bed. Figure 9 shows the Auto-trans. 


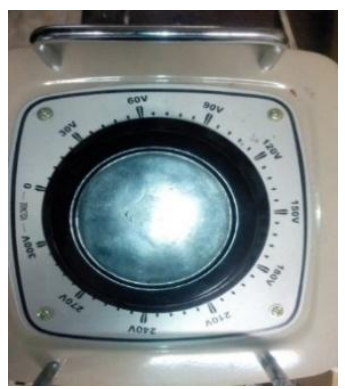

Fig9. Auto-trans

\section{Governing Equations}

Reynolds number calculated as below:

Where the $\mathrm{u}$ is the air velocity, $\rho$ is the Density equals to $1.177, \mathrm{D}_{\mathrm{h}}$ is the equivalent hydraulic diameter and $\mu$ is the dynamic viscosity equals to $1.864 \times 10-5$. The heat transfer coefficient obtained as below:

Where the $\mathrm{q}$ is the heat flux and $\mathrm{q}_{\text {loss }}$ is the loss flux that considered 5 to $20 \%$ of heat flux. The loss flux in this study considered $5 \%$ because of suitable insulation. Tw and Tb are the temperature of wall and canal center respectively. Nusselt number $(\mathrm{Nu})$ obtained as below:

Where $\mathrm{k}$ is, the air heat conductivity equals to 0.0245 . Average $\mathrm{Nu}$ calculated as below:

Relation 5 shows the friction coefficient equation.

Where $\mathrm{L}$ is the length of part that pressure loss measured along it.The coefficient of thermal performance calculated as below:

The Nu and f compared with relations 7 (Kakac and Spalding, 1979) and eight (Han et al, 1984) for validation assessment. 


\section{Results}

In this part, for the comparison and validation, results of without jag surface measurements compared with obtained results of relations 7 and 8 for different Reynolds. As it can be seen in figures 10 and 11, there is suitable compatibility between the experiment results and the relations 7 and 8 .

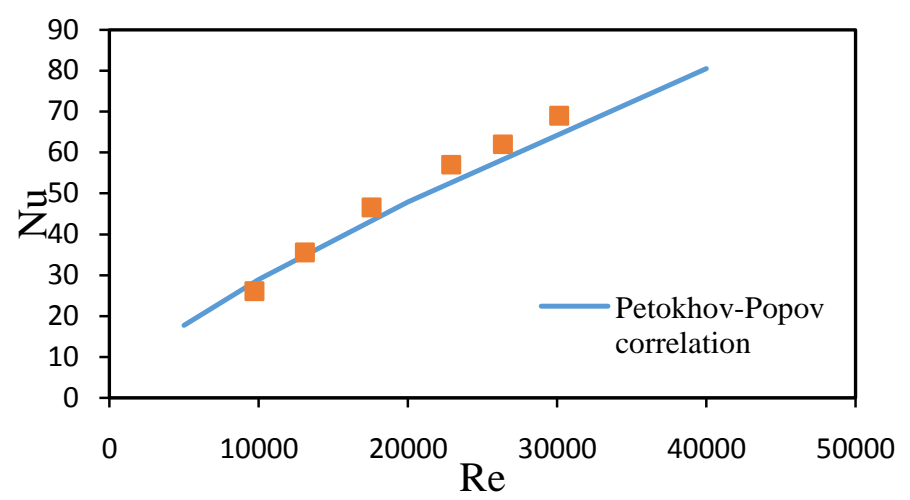

Fig10. $\mathrm{Nu}$ in compare to Petokhov-Popov relation

\section{Effect of jags Step-height ratio}

Figures 11, in 12 and 13 show the heat transfer trend in the middle of jags, in jag height ratio to hydraulic diameter equal to 0.0685 and at $90^{\circ}$ attack angle respectively for three step-height ratio of 10,20 and 40 in Reynolds 13000, 22000 and 30000. As it can be seen, at first in all steps, the heat transfer is high because of the high temperature gradient and lack of boundary layer; during the $\mathrm{X} / \mathrm{D}_{\mathrm{h}}$ increasing and boundary layer generation, the $\mathrm{Nu}$ changes reduce rapidly and will be constant.The changes of $\mathrm{Nu}$ is more in the beginning of canal in step-height ratio equal to 10 . Decreasing the ratio, the length of entrance area declines because of the flow turbulence increasing. The number of jags, reaching the improved state in step-height ratios 10, 20 and 40 are five, three and two respectively. In addition, in step-height ratio equal to 10, along with Reynolds increasing, the overshoot amount reached from $58.3 \%$ to $60 \%$ whereas for steps 20 and 40 it reached from 50.3 to $53 \%$ and 39.8 to $43.4 \%$ respectively.

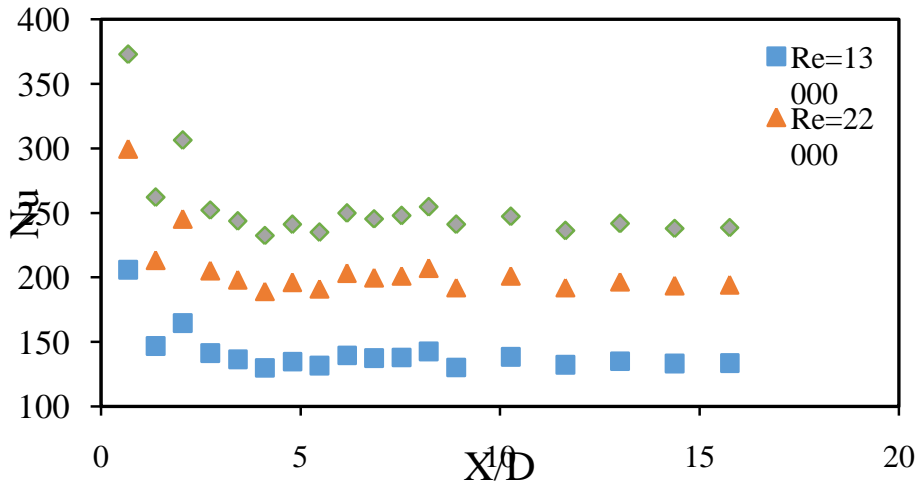

Fig11. $\mathrm{Nu}$ changes in the middle of jags per canal length for $\mathrm{P} / \mathrm{e}=10, \mathrm{e} / \mathrm{D}=0.068 \mathrm{and} \theta=90$

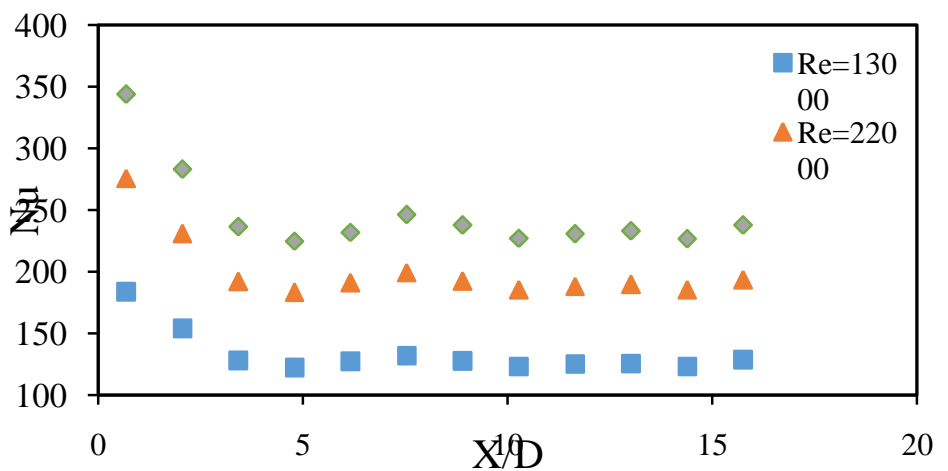

Fig12. $\mathrm{Nu}$ changes in the middle of jags per canal length for $\mathrm{P} / \mathrm{e}=20, \mathrm{e} / \mathrm{D}=0.068 \mathrm{and} \theta=90$ 


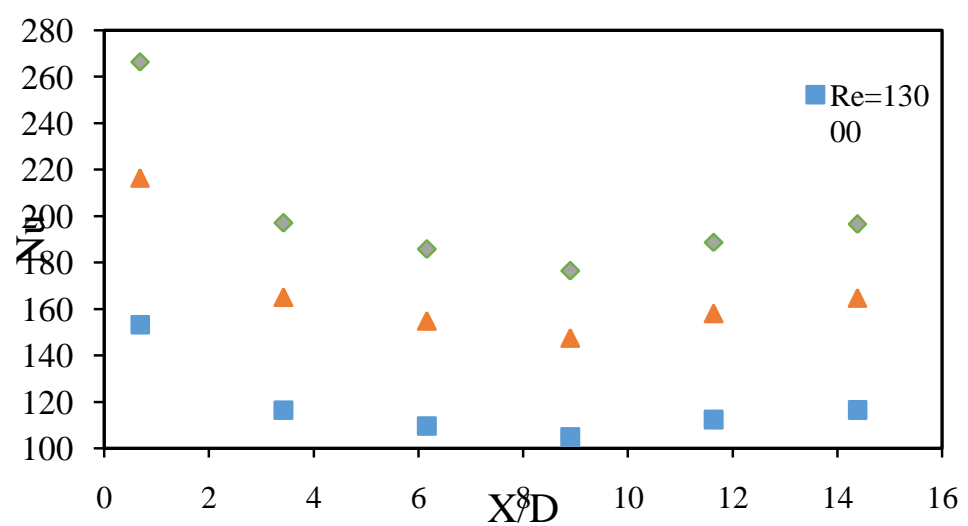

Fig13. $\mathrm{Nu}$ changes in the middle of jags per canal length for $\mathrm{P} / \mathrm{e}=40, \mathrm{e} / \mathrm{D}=0.068$ and $\theta=90$

\section{Effect of jags height to canal hydraulic diameter}

Figures 11, 14 and 15 show the heat transfer along the canal for step-height 10 for Reynolds 13000, 22000 and 30000 for 3 different height-hydraulic diameter $0.0685,0.137$ and 0.205 .

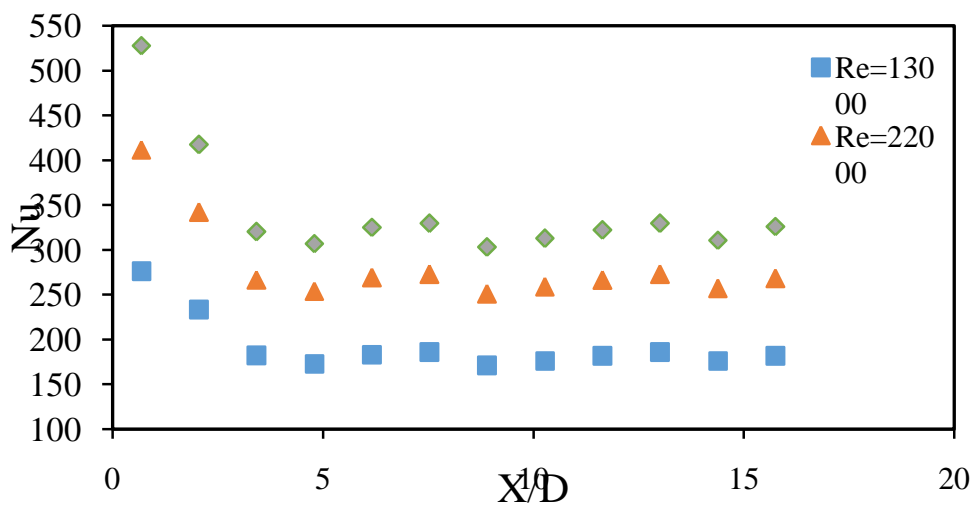

Fig14. $\mathrm{Nu}$ changes in the middle of jags per canal length for $\mathrm{P} / \mathrm{e}=10, \mathrm{e} / \mathrm{D}=0.137$ and $\theta=90$

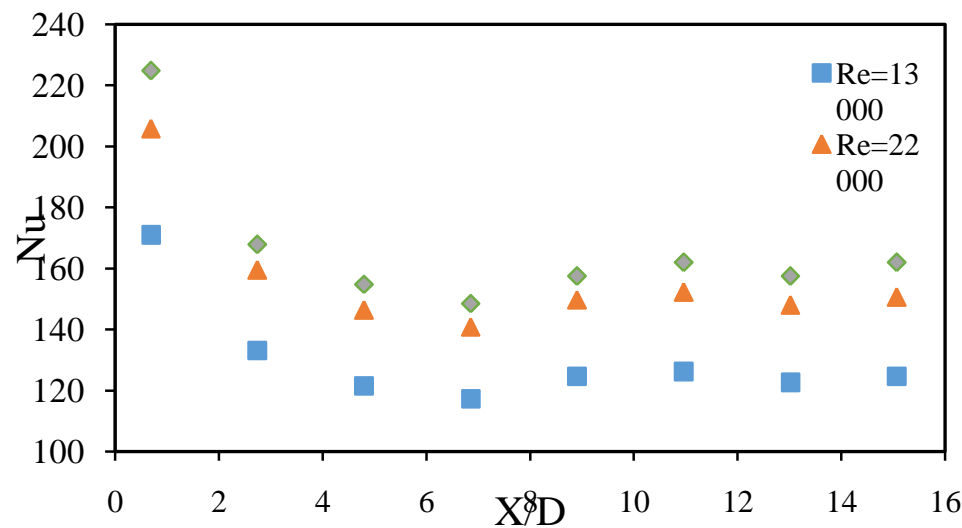

Fig15. $\mathrm{Nu}$ changes in the middle of jags per canal length for $\mathrm{P} / \mathrm{e}=10, \mathrm{e} / \mathrm{D}=0.205 \mathrm{and} \theta=90$

In the lowest amount of height ratio, the changes are more than other heights. Increasing the ratio, the changes decreased because of more flow turbidity. Second reason maybe the more distance between the jags. In each ratio the Reynolds, changes did not have considerable effect on general trend of heat transfer. For the three height ratio of $0.0685,0.137$ and 0.205 the number of jags for the improvement are 5, 3 and 2 respectively. The length of entrance area was constant in response of height-hydraulic diameter ratio and fixing the step-height ratio from 0.685 to 0.137 . It a bit decreased at 0.137 to 0.205 changing. In addition, the overshoot amount in Reynolds 22000 obtained for each one of jags heights equal to $58 \%, 62 \%$ and $40 \%$. 


\section{Conclusion}

In this article, an experimental device was made for evaluating the heat transfer and pressure loss in heat exchange canals, with turbine blades cooling application in turbojets by the thin jags. At first, the obtained results for turbojet blades simulation evaluated for a canal without any jag. The results showed suitable accommodation. Study shows that canal roughing caused the reduction of entrance area length and overshooting because of the flow more turbidity. Reducing the step-height ratio, the jag number along the flow path will increase and heat transfer increases consequently. Increasing the jags step, the distance between the flow return and separation point will increase that causes the boundary layer expansion and decreasing the average heat transfer consequently. The entrance length decreases via the step-height ratio decreasing but there is not considerable change for entrance area via the height-hydraulic diameter changes.

\section{References}

[1]. j. c. Han, J. S. Park and C. K. Lei, November 1984. "Heat Transfer and Pressure Drop in Blade Cooling Channels With Turbulence Promoters", NASA.

[2]. Gao A., Wenxian Lin A. B., Tao Liu a., Chaofeng Xia., 2006. "Analytical and experimental studies on the thermal performance of cross-corrugated and flat-plate solar air heaters", Applied Energy, Vol. 84, pp. 425-441.

[3]. K. R. Aharwala., B. K. Gandhib., J. S. Sainib., 2008. "Experimental investigation on heat-transfer enhancement due to a gap in an inclined continuous rib arrangement in a rectangular duct of solar air heater", Renewable Energy, Vol. 33, pp. 585-596.

[4]. Han J. C., Glicksman L. R., Rosenow W. M., 1978. "Investigation of heat transfer and friction for rib-roughened surfaces". Int J Heat Mass Transfer, Vol. 21, pp. 1143-56.

[5]. J. C. Han., J. S. Park., C. K. Lei., 1985. "Heat Transfer Enhancement in Channels with Turbulence Promoters", ASME J. Eng. Gas Turb, Vol. 107, pp. 628-635.

[6]. Han J. C., Park J. S., 1988. "Developing heat transfer in rectangular channels with rib turbulators”. Int J Heat Mass Transfer, Vol. 3, pp. 183-95.

[7]. Han J. C., Zhang Y. M., 1992. High performance heat transfers ducts with parallel broken and V-shaped broken ribs". Int J Heat Mass Transfer, Vol. 35, pp. 513-23.

[8]. Kiml R, Mochizuki S, Murata A, 2001. "Effects of rib arrangements on heat transfer and flow behavior in a rectangular rib roughened passage". J Heat Transfer, Vol. 123, pp. 675-81.

[9]. Lau S. C., McMillin R. D., Han J. C., 1991. "Turbulent heat transfer and friction in a square channel with discrete rib turbulators". Trans ASME, J Turbo Machinery, Vol. 113, pp. 360-6.

[10]. Lau S. C., McMillin R. D., Han J. C., 1991. "Heat transfer characteristics of turbulent flow in a square channel with angled rib". Trans ASME, J Turbomachinery, Vol. 113, pp. 367-74

[11]. Cho H. H., Wu S. J., Kwon H. J., 2000. "Local heat/mass transfer measurement in a rectangular duct with discrete ribs". J Turbomachinery, Vol. 122, pp. 579-86.

[12]. O'Doherty T., Jolly A. J., Bates C. J., 2001. "Optimisation of heat transfer enhancement devices in a bayonet tube heat exchanger". Appl Therm Eng, Vol. 21, pp. 19-36.

[13]. Liou T. M., Hwang J. J., Chen S. H., 1993. "Simulation and measurement of enhanced turbulent heat transfer in a channel with periodic ribs on one principal wall”. Int J Heat Mass Transfer, Vol. 36, pp. 507-17.

[14]. Ryu D. N., Choi D. H., Patel V. C., 2007. "Analysis of turbulent flow in channels roughened by two-dimensional ribs and threedimensional blocks". Part I: Resistance. Int J Heat Fluid Fl, Vol. 28, pp. 1098-111.

[15]. Ryu D. N., Choi D. H., Patel V. C., 2007. "Analysis of turbulent flow in channels roughened by two-dimensional ribs and threedimensional blocks". Part II: Heat transfer. Int J Heat Fluid Fl, Vol.28, pp. 1112-24.

[16]. Bilen K., Cetin M., Gul H., Balta T., 2009. "The investigation of groove geometry effect on heat transfer for internally grooved tubes", Appl. Therm. Eng, Vol. 29, pp. 753-761.

[17]. P. W. Dittus and L. M. K. Boelter., 1985. "Heat transfer in automobile radiators of the turbular type", Univ. Calif. Publ. Eng., Vol.2, No. 13, Oct. 17, 1930, pp 443-461; reprinted in Int. Cmmun. Heat Mass Transfer, Vol. 12, pp. 3-22.

[18]. S. Kakac, and D. Spalding, 1979. "Turbulent Forced Convection in Channels and Bundles", New York: Hemisphere Publishing Corp. 